\title{
LOGÍSTICA: UM DESAFIO A SER EXPLORADO PARA ALCANÇAR A VANTAGEM COMPETITIVA
}

\author{
Bárbara Gomes Felício, Munir Jorge Felício
}

Universidade do Oeste Paulista - UNOESTE. Pós-graduação em Gestão em Marketing e Comunicação, Presidente Prudente - SP. E-mail: barbara gfelicio@hotmail.com

\begin{abstract}
RESUMO
A logística é o processo de gerenciar estrategicamente a aquisição, movimentação e armazenagem de materiais, peças e produtos acabados através da organização e seus canais de marketing, de modo a poder maximizar as lucratividades presente e futura através do atendimento dos pedidos a baixo custo. Destaca-se a Logística e sua atividade de distribuição física, uma vez que esta é responsável pela gestão dos materiais desde a saída do produto acabado na linha de produção até a entrega do mesmo ao consumidor final. Isto quer dizer que, a distribuição física é uma das atividades mais complexas da logística, já que qualquer atraso na entrega do produto acabado reflete diretamente no pronto atendimento do cliente e consequentemente em sua satisfação.

Sendo assim, é necessário compreender a Logística como diferencial competitivo capaz de agregar valor a bens e serviços à partir do alinhamento do planejamento logístico e de marketing.

Palavras-chave: Logística, distribuição Física, marketing, competitividade, lucratividade.
\end{abstract}

LOGISTIC: A CHALLENGE TO BE EXPLORED TO ACHIEVE A COMPETITIVE ADVANTAGE

\begin{abstract}
Logistics is the process of strategically managing the procurement, movement and storage of materials, parts and finished products through the organization and its marketing channels in order to maximize current and future profitabilities through order fulfillment at low cost.

Stands out the logistics of physical activity and its distribution, since it is responsible for the management of materials from the output of the finished product on the production line to the delivery of the same to the end consumer. This means that the physical distribution is one of the most complex activities of logistics, since any delay in delivery of the finished product is directly reflected in customer responsiveness and consequently in their satisfaction. Therefore, it is necessary to understand the logistics as a competitive advantage capable of adding value to goods and services from the alignment of the logistical planning and marketing
\end{abstract}

Keywords: Logistics, Physical Distribution, marketing, competitiveness and profitability. 


\section{INTRODUÇÃO}

A logística e sua atividade de distribuição física, uma vez que esta é responsável pela gestão dos materiais desde a saída do produto acabado na linha de produção até a entrega do mesmo ao consumidor final.

Isto quer dizer que a distribuição é uma das atividades mais complexas da logística, já que qualquer atraso na entrega do produto acabado reflete diretamente no pronto atendimento do cliente e consequentemente em sua satisfação.

A distribuição também envolve a utilização de modais de transportes, os quais consomem uma parcela elevada do custo total da empresa e que em decorrência disso pode acabar encarecendo o produto.

O presente estudo buscou analisar a logística como um desafio a ser explorado, para alcançar a vantagem competitiva de uma organização.

\section{METODOLOGIA}

Para realização desta pesquisa e que foi de extrema importância para a obtenção dos objetivos, foi à coleta de dados através de um estudo bibliográfico ou de informações já existentes. Conforme Lakatos e Marconi (1985, p. 22) comentam a pesquisa bibliográfica é aquela realizada em artigos, livros e publicações, os quais proporcionam várias informações válidas de fatos ocorridos, através de fontes seguras e concretas sobre o assunto.

Também esta pesquisa coletou dados por meio do estudo de caso que de acordo com Gil (1994), trata-se de um estudo profundo e exaustivo de um ou poucos objetos, de maneira que permita seu extenso e detalhado conhecimento. Desta forma, o estudo de caso, baseia-se na coleta de informações através de um estudo profundo e extenuante, onde detalhes proporcionam conhecimento sobre o objeto ou o caso estudado.

\section{Logística}

A logística desde as guerras militares era usada para tramar estratégias e com o objetivo de transportar soldados, armas e remédios na hora certa com mínimo de tempo possível. As guerras eram distantes e longas, assim demandava deslocamento constante e o planejamento era necessário para a definição de rotas para locais com água potável, transporte, armazenagem e distribuição.

Com base na definição apresentada pelo referido dicionário, verifica-se que a origem e o conceito do termo logística esta diretamente relacionados com as estratégias militares com o 
planejamento de batalhas, armazenagem e distribuição de materiais e tropas. Portanto, essa definição não traz a real importância da logística nas organizações por se limitar a arte da guerra e a ciência militar. Outros autores comprometidos no assunto procuraram adequá-los ao contexto das organizações.

Definição de logística para Novaes (2007, p. 35);

Logística é o processo de planejar, implementar e controlar de maneira eficiente o fluxo e a armazenagem de produtos, bem como os serviços e informações associados, cobrindo desde o ponto de origem até o ponto de consumo, com o objetivo de atender aos requisitos do consumidor

De acordo com Christopher (2009, p. 3)

Logística é o processo de gerenciamento estratégico da compra, do transporte e da armazenagem de matérias-primas, partes e produtos acabados (além dos fluxos de informação relacionados) por parte da organização e de seus canais de marketing, de tal modo que a lucratividade atual e futura sejam maximizadas mediante a entrega de encomendas com o menor custo associado.

Nessa projeção dos princípios estudados pelos autores sobre a definição do assunto, evidencia-se a logística como o processo organizado de implementar, controlar e distribuir serviços para alcançar a demanda e satisfazer as necessidades e desejos dos clientes.

\section{Importância da Logística}

Atualmente as empresas buscam maior competitividade, maior ofertas de produtos e serviços adequados à exigência dos clientes, desenvolvimento tecnológico e capital intelectual. Para as organizações enfrentarem esse desafio, buscam a redução dos custos, e a logística é um diferencial que as empresas buscam para a inserção de seus produtos e serviços no mercado competitivo.

Segundo Fleury (2000 p. 21):

No entanto, esse esforço empresarial esbarra nas enormes deficiências ainda hoje encontradas na infra-estrutura de transportes e comunicações. Existem aí enormes oportunidades para aumento de produtividade e melhoria da qualidade de serviços.

Como destacado na citação acima, o autor levanta uma questão séria enfrentada pelas organizações atualmente, a logística tem seu papel fundamental nas empresas para a administração de produção e distribuição dos produtos, mas há dificuldade no escoamento desses produtos, pois o transporte e a comunicação são precários. 


\section{Gestão de Transporte}

A gestão de transporte baseia- se na movimentação e direcionamento dos bens e serviços onde exista demanda. O transporte é uma das principais funções logística e representa maior custo dentro de uma organização. As principais funcionalidades do transporte dentro do universo logístico estão reunidas ás dimensões de espaço físico e tempo, ou seja, disponibilizar o produto desejado dentro do prazo correto, atendendo as necessidades do consumidor, utilizando recursos menos custosos.

Nesse contexto Fleury,(2000) comenta que mesmo com os atributos que o avanço tecnológico dispõem para a troca de informações em tempo real, o transporte prossegue sendo fundamental para que seja alcançado o objetivo, que é, o produto certo, na quantidade certa, na hora certa, no lugar certo ao menor custo possível.

Em busca para atingir tal objetivo em suas operações logísticas, empresas brasileiras, aprimoram o transporte, empregando recursos financeiros em tecnologia da informação objetivando melhor planejamento e controle da operação, adaptando as cargas em modais adequados possibilitando redução nos custos.

\section{Importância e finalidade}

Durante muito tempo, a qualidade de movimentação e transferência de bem e serviços prestadas ao cliente não foram apreciadas pelas empresas devido à falta de investimento no âmbito de transporte, como modais adequados, planejamento de rotas, informações em tempo real, controle sobre cargas e mais. Contudo, a pressão dos clientes para melhores serviços e/ou produtos no desempenho da entrega no prazo correto e produtos em perfeito estado, concorrência acirrada, e oportunidades que agregam valores para empresa, destacando uma vantagem competitiva, tudo isso, obrigaram gestores de empresas a modificar e reestruturar as funções de transporte para tornar-se aptas as necessidades e expectativas que o mercado consumidor exigia, como também garantir a competitividade e a lucratividade.

Neste contexto, Tontini e Zanchett (2010) comentam que os clientes estão se tornando cada vez mais exigentes, onde seus níveis de conhecimento e de percepção acerca das características de qualidade dos produtos e serviços estão em evidência. Além disso, o grau de satisfação desses clientes está condicionado ao desempenho efetivo dos atributos do serviço prestado e ao real atendimento de suas necessidades explícitas e implícitas. 
No que refere-se à satisfação das necessidades do clientes, Bowersox e Closs (2010) ponderam que em essência, o marketing como uma função organizacional, fundamenta-se no reconhecimento e correspondência das necessidades específicas do cliente.

Do mesmo modo, Kotler e Keller (2006, p. 4, grifo do autor) sustentam que "O marketing envolve a identificação e a satisfação das necessidades humanas e sociais".

Contudo, os dois autores anunciam que o marketing é responsável por proporcionar o valor pedido ao cliente mediante a identificação, produção e entrega do produto e/ ou serviços que satisfação suas necessidades.

Conforme a narrativa dos autores a cima, entende-se que as atribuições da logística empresarial concorrem para a realização da missão do marketing ou seja, para que o marketing seja executado com sucesso, os bens e/ou serviço devem estar a disposição do cliente, em tempo hábil, e no local mais apropriado para que o mesmo consiga, possa atender suas necessidades mediante ao desenvolvimento da atividade logística.

Segundo Hijjar (2000, p. 57,), não se pode duvidar que "O serviço ao cliente é cada vez mais valorizado, tanto pelos consumidores finais quanto pelos clientes institucionais, pois apenas bons produtos e bons preços não são suficientes para atender às exigências de uma transação comercial".

Entretanto, assim, destaca-se que o serviço prestado ao cliente tem se mostrado como uma estratégia fundamental, para aumentar a participação de uma organização no mercado atual, conquistando a confiança do consumidor e consequentemente sua preferência.

Já Christopher (2009, p. 45, grifo nosso) sugere que serviço logístico é

[...] oferecer "utilidade de tempo e lugar" na transferência de bens e serviços entre comprador e vendedor. Ou seja, não há nenhum valor no produto ou serviço até estar nas mãos do cliente ou consumidor. Daí se conclui que tornar o produto ou serviço "disponível" é, em essência, o significado da função distribuição de um negócio. "Disponibilidade" é um conceito complexo que envolve um conjunto de fatores que, juntos, constituem o serviço ao cliente.

Na ótica do autor, o serviço ao cliente é formado por vários fatores que deixam o produto disponível, para que o serviço de bens e serviços sejam executados de forma eficiente sendo elevadas pelas variáveis "tempo e Lugar" produzindo assim valor ao produto.

Sob o enfoque do serviço logístico, Tontini e Zanchett (2010) afirmam que a variabilidade do nível de serviço prestado pelas empresas pode levar os clientes a optarem por outros fornecedores disponíveis no mercado para suprirem suas necessidades. Fleury, Wanke e Figueiredo (2000), também enfatizam que com as mudanças no padrão de consumo e o novo 
estilo de vida dos consumidores, a qualidade do serviço tem sido elemento-chave no momento de decisão de compra. Fatores como, demora ou inconsistência nas entregas, a falta de produtos nas gôndolas do varejo, entre outros, implicam em vendas não realizadas, perda e insatisfação dos clientes.

Diante das narrações apresentadas até aqui, basta analisar os conceitos de nível de serviço logístico expressos na literatura. Pela ótica do marketing, Kotler e Keller (2006, p. 397) definem o serviço como "qualquer ato ou desempenho, essencialmente intangível, que uma parte pode oferecer a outra e que não resulta na propriedade de nada. A execução de um serviço pode estar ou não ligada a um produto concreto"

Nota-se que o termo "serviço" é narrada como algo intangível ou seja, que não conseguimos apanhar, algo não material, intocável, impalpável, assim, compreende-se que é todo e qualquer serviço que a empresa presta para o cliente.

Diferente disso, Ballou (2011, p. 73) esclarece que,

Nível de serviço logístico é a qualidade com que o fluxo de bens e serviços é gerenciado. É o resultado líquido de todos os esforços logísticos da firma. É o desempenho oferecido pelos fornecedores aos seus clientes no atendimento dos pedidos. O nível de serviço logístico é fator-chave do conjunto de valores logísticos que as empresas oferecem a seus clientes para assegurar sua fidelidade.

Com fundamento nesse contexto, conclui-se que nível de serviço é a qualidade do desempenho relacionado são fluxo logístico de uma empresa, ou melhor, é o resultado sinérgico da cadeia de suprimentos levados ao atendimento dos pedidos dos clientes, bem como a oferta de valores para garantir sua fidelidade e satisfação.

\section{CONCLUSÃO}

Atingir o consumidor final com celeridade, oferecendo produto que priorize sua qualidade é fundamental para qualquer organização empresarial, neste contexto, as empresas brasileiras têm como base a Logística, sendo essa uma atividade essencial para o escoamento dos seus produtos.

Conclui-se que com logística é possível aumentar a competitividade entre as empresas no dia de hoje, podendo assim determinar o fracasso ou o sucesso da organização. As atividades desenvolvidas pela logística trata-se, de uma ferramenta que contribui para um bom planejamento na distribuição de produtos, aquisição de matéria-prima e armazenamento, possibilitando a redução dos custos e o aumento da competitividade. 


\section{REFERÊNCIAS}

BALLOU, R. H. Logística empresarial: transportes, administração de materiais e distribuição física. trad. Hugo T. Y. Yoshizaki. 1. ed. 24. reimpr. São Paulo: Atlas, 2011.

BOWERSOX, D. J.; CLOSS, D. J. Logística empresarial: o processo de integração da cadeia de suprimento. trad. Equipe do Centro de Estudos em Logística, Adalberto Ferreira das Neves. 1. ed. 9 reimpr. São Paulo: Atlas, 2010.

CHRISTOPHER, M. Logística e gerenciamento da cadeia de suprimentos: criando redes que agregam valor. trad. Mauro de Campos Silva. 2 ed. São Paulo: Cengage Learning, 2009.

FLEURY, P. F.; WANKE, P.; FIGUEIREDO, K. F. Logística empresarial: A Perspectiva Brasileira. São Paulo: Atlas, 2000.

FLEURY, P. F.; WANKE, P.; FIGUEIREDO, K. F. Logística empresarial: a perspectiva brasileira. 1. ed. São Paulo: Atlas, 2000.

GIL. A. C. Métodos e técnicas de pesquisa social. São Paulo: Atlas,1994.

HIJJAR, M. F. Segmentação de mercado para diferenciação dos serviços logísticos. In: FLEURY, P. F.; WANKE, P.; FIGUEIREDO, K. F. Logística empresarial: a perspectiva brasileira. 1. ed. São Paulo: Atlas, 2000. p. 57-64.

LAKATOS, E. M.; MARCONI, M. A. Técnicas de pesquisa : planejamento e execução de pesquisas, amostragens e técnicas de pesquisa, elaboração, análise e interpretação de dados. 1 ed. São Paulo: Atlas,1985.

TONTINI, G.; ZANCHETT, R. Atributos de satisfação e lealdade em serviços logísticos. Gestão \& Produção. São Carlos, v. 17, n. 4, p. 801-816, out./dez. 2010. Disponível em: <http://www.scielo.br/pdf/gp/v17n4/a13v17n4.pdf>. Acesso em: 20 de outubro 2013.

KOTLER, P.; KELLER, K. L. Administração de marketing. trad. Mônica Rosenberg, Cláudia Freire, Brasil Ramos Fernandes. rev. Dilson Gabriel dos Santos. 12. ed. São Paulo: Pearson Prentice Hall, 2006.

NOVAES, A. G. Logística e gerenciamento da cadeia de distribuição. Campinas: SP, 2007. 